\title{
PReS-FINAL-2045: Mutational analysis of sialic acid acetylesterase (siae) in juvenile idiopathic arthritis (JIA)
}

\author{
E Tsitsami ${ }^{1 *}$, E Sevdali $^{2}$, M Speletas ${ }^{2}$ \\ From 20th Pediatric Rheumatology European Society (PReS) Congress \\ Ljubljana, Slovenia. 25-29 September 2013
}

\section{Introduction}

SIAE is involved in the maintenance of immunological tolerance through negative regulation of B-cell receptor (BCR) signaling. Recent evidences, though conflicting, indicate that rare loss-of-function SIAE variants are associated with susceptibility to various autoimmune diseases. Advances in understanding JIA pathophysiology have led to the consensus that systemic JIA (SIIA) is an autoinflammatory disorder while oligo/polyarticular JIA (O/PJIA) is an antigen-driven lymphocytemediated autoimmune disease.

\section{Objectives}

To elucidate whether SIAE variants predispose their carriers to O/PJIA but not to SJIA.

\section{Methods}

Sixty-five JIA patients (M/F: 19/46, mean age: 9.8 years, range:2.5-18.3; 57 with O/PJIA and 8 with SJIA) and 82 age- and sex-matched healthy controls were enrolled. Amplification of all 10 SIAE exons, including exonintron boundaries, and sequencing of purified products were performed.

\section{Results}

Two novel heterozygous SIAE mutations, namely the Q343P (g.41498 A > C, c.1028A > C) and the Y495X (g.44266C > A, c.1485C > A), as well as three already described heterozygous SIAE mutations, namely the functionally innocent M89V (g.20536A > G) mutation and the silent mutations S156S (g.26573T > C) and T484T (g.44233G > A) were found in O/PJIA patients.

${ }^{1}$ 1st Department of Pediatrics, School of Medicine, University of Athens, Children's Hospital "Aghia Sophia", Athens, Greece

Full list of author information is available at the end of the article
The girl carrying the Q343P mutation had ANA(+) persistent oligoarthritis. Her family study proved that her father, having a family history of autoimmune disease, was also carrier of the same mutation. The girl with the Y495X mutation suffered from RF(-), ANA(+) polyarthritis. The novel SIAE mutations did not detected among normal controls. Amongst the patients with SJIA, one was heterozygote for the known functionally innocent K71R (g.11927A > G) and A467V (g.44181C > T) mutations as well as for the silent mutations $\mathrm{T} 484 \mathrm{~T}$ and S156S, while another one was heterozygote for the silent mutation R340R (g. $41490 \mathrm{~T}>$ C).

\section{Conclusion}

Our results support the notion that SIAE might be involved to the pathogenesis of O/PJIA but not of SJIA. Functional analysis of the identified novel SIAE variants is required to prove the biological significance of these genetic alterations.

\section{Disclosure of interest}

None declared.

Authors' details

${ }^{1}$ 1st Department of Pediatrics, School of Medicine, University of Athens, Children's Hospital "Aghia Sophia", Athens, Greece. 'Department of Immunology \& Histocompatibility, School of Medicine, University of Thessaly, Larissa, Greece.

Published: 5 December 2013

doi:10.1186/1546-0096-11-S2-P58

Cite this article as: Tsitsami et al:: PReS-FINAL-2045: Mutational analysis of sialic acid acetylesterase (siae) in juvenile idiopathic arthritis (JIA). Pediatric Rheumatology 2013 11(Suppl 2):P58.
C Biomed Central

(c) 2013 Tsitsami et al.; licensee BioMed Central Ltd. This is an Open Access article distributed under the terms of the Creative Commons Attribution License (http://creativecommons.org/licenses/by/2.0), which permits unrestricted use, distribution, and reproduction in any medium, provided the original work is properly cited. The Creative Commons Public Domain Dedication waiver (http://creativecommons.org/publicdomain/zero/1.0/) applies to the data made available in this article, unless otherwise stated. 